\title{
La evolución del proyecto de nación sinarquista (Del autoritarismo conservador a la democracia cristiana 1949-1971)
}

\author{
José Antonio NúÑEZ OCHOA \\ Universidad Anáhuac México, Facultad de Derecho, México \\ Austreberto Martinez Villegas, La evolución del proyecto de nación sinarquista \\ (Del autoritarismo conservador a la democracia cristiana 1949-1971), \\ México, Universidad Autónoma Metropolitana, 2020, 261 pp. \\ ISBN 978-607-28-1945-0.
}

https://doi.org/10.36105/iut.2021n34.11

La obra que se reseña analiza al sinarquismo, que es un movimiento social sobre el que se han escrito los más contradictorios comentarios, que van desde considerarlo como la versión mexicana del nazi-fascismo, hasta de ser el brazo político de la Iglesia Católica, pasando por ser una no deseada consecuencia de la ineficacia de la lucha armada que ensangrentó México, entre los años 1926 y 1929.

Dado que el autor es doctor en Historia Moderna Contemporánea, aborda con toda rigurosidad el tema de la Unión Nacional Sinarquista (UNS), partiendo de una exhaustiva relación - debidamente comentada - sobre lo que se ha escrito tanto por quienes han sido sus militantes, como por quienes han sido sus adversarios, lo que permite que se identifique la impronta que su sucesivos líderes le han ido dejando, siempre relacionándolo con el entorno nacional e internacional, que rodeó fundación, en León, Gto., el 23 de mayo de 1937, habiendo sido su primer dirigente José Trueba Olivares y siendo sus primeros asesores los jesuitas Julio Vértiz, Eduardo Iglesias y José María Heredia.

Desde su fundación hasta la actualidad, el autor hace un recorrido minucioso sobre la vida de este movimiento social, haciendo principal hincapié en lo acontecido durante los años que se señalan en el subtítulo, porque ese intervalo responde a un cambio en la UNS, de la cual nació un partido político, con reconocimiento oficial, el Partido Demócrata Mexicano (PDM), aunque ya el 13 de mayo de 1946 había creado el Partido Fuerza Popular, que en 1949 perdió su 
registro por haber cometido el error político de "encapuchar" la estatua de Benito Juárez que está en el hemiciclo de la capital mexicana.

Como bien afirma el autor, el nacimiento de cualquier movimiento de esta índole - y el sinarquismo no es la excepción - responde a su tiempo y a su circunstancia. De esa forma, en una primera instancia el autor evidencia la influencia que tuvo en su creación la llamada "doctrina social de la Iglesia", principalmente de las encíclicas "Rerum novarum" (Papa León XIII, 15 de mayo de 1891) y de la "Quadragesimo anno" (papa Pío XI, 15 de mayo de 1931), las cuales analiza el autor y las relaciona con los principales postulados de la Unión Nacional Sinarquista, relacionados con el derecho de propiedad, los derechos laborales y la organización política de la sociedad, y con la participación política de los católicos, postulados que fueron una respuesta a los movimientos sociales derivados del auge de las teorías socialistas y de la anarquía que siguió en las naciones vencidas al término de la Gran Guerra, con el consiguiente reacomodo de los centros de poder.

En efecto, en los años anteriores al surgimiento del grupo sinarquista, el mundo en general - y México en particular - estaban viviendo cambios profundos en sus estructuras. Después de derrocamiento de los zares, había surgido la Unión de Repúblicas Socialistas Soviéticas (Soyuz Soviétskij Sotsialistícheskij Respúblik), con la declarada intención de expandir el comunismo por todo el mundo, por medio del Komintern (Organización comunista, fundada por Lenin en 1919, para luchar contra el capitalismo en todo el mundo).

Después de la "marcha sobre Roma", Benito Mussolini, con sus camisas negras y con sus Fasci italiani di combattimento, se había hecho del poder en la Italia de 1922, iniciando la era del fascismo, que el autor analiza en sus principales características.

Por otra parte, en la primera posguerra, Alemania había entrado en una crisis política y económica (causada por su derrota y por el tratado de Versalles), que la constitución de Weimar (sancionada 14 de agosto de 1919), no pudo evitar. A la hiperinflación le acompañaban más de seis millones de alemanes sin trabajo. Precisamente en esa constitución se establecía que habría un presidente elegido por votación popular que tendría, entre otras facultades, la de elegir al canciller para que formara gobierno. En 1933 había habido elecciones en Alemania y el grupo político más votado (con el $43.91 \%$ ) fue el Partido Nacionalsocialista Obrero Alemán, por lo que el presidente Paul von Hindenburg, nombró canciller de Alemania a Adolfo Hitler, comenzado así la época del nazismo.

En México se estaba viviendo la postrevolución. Los líderes del grupo triunfante tenían antagonismos $\mathrm{y}$, sin que fuera uno de los principales postulados de la convocatoria al levantamiento armado, por muchos medios se inició una abierta lucha con la Iglesia Católica.

Como lo comenta el autor, ya había existido un Partido Católico Nacional (su lema era "Dios, Patria y Libertad") que, a pesar de haber tenido varios triunfos electorales, se desprestigió al apoyar la presidencia de Victoriano Huerta. Sin embargo, con la promulgación de la Constitución de 1917, se evidenció un marco 
normativo notoriamente adverso a la Iglesia Católica, por lo que el enfrentamiento con ella era inevitable. Entre otras restricciones constitucionales, se puede mencionar que se prohibían los votos religiosos; se prohibía el establecimiento de órdenes monásticas; se exigía ser mexicano por nacimiento para poder ser ministro de culto; se prohibía a los ministros de culto intervenir en la educación; todos los templos quedaban bajo el dominio del gobierno; los ministros de culto no tendrían voto activo ni pasivo y no se reconocía personalidad jurídica a las iglesias. ${ }^{1}$

La estabilidad política era precaria. ${ }^{2}$ Seguían los levantamientos militares. Finalmente llega al poder Plutarco Elías Calles (1924-1928) quien posteriormente "institucionalizó" a la revolución, por medio de la creación, en 1929, de un partido político, el Partido Nacional Revolucionario, que en 1938 se convirtió en el Partido de la Revolución Mexicana y que desde 1946 es el Partido Revolucionario Institucional.

Durante su gobierno, el presidente Calles, haciendo uso de facultades extraordinarias para legislar, hizo y promulgó la llamada "Ley Calles", ${ }^{3}$ por medio de la cual, en la práctica, hacía imposible el culto católico, a lo que el clero respondió cerrando todas las iglesias de México y, parte de él, apoyó el movimiento armado llamado "La Cristiada" (1926-1929), el cual terminó con unos "Acuerdos", mediante los cuales "Los cristeros" deponían las armas sin que se abrogaran las leyes anticatólicas - que habían provocado el levantamiento armado- pero que, en la práctica, ya no se aplicarían. ${ }^{4}$

Muchos de los antiguos cristeros no estuvieron de acuerdo con esos "arreglos" y querían seguir luchando contra el régimen nacido de la revolución y que había propiciado inestabilidad y gran pérdida de vidas humanas. Se sentían traicionados por el alto clero y por el gobierno que había pactado su rendición, sin haber tenido ellos participación en las negociaciones. ${ }^{5}$

\footnotetext{
Lo cual no fue óbice para que, por medio de un decreto, el presidente Álvaro Obregón permitiera la entrada del grupo religioso "los menonitas", con sus ministros extranjeros, en 1921.

2 El gobierno de los Estados Unidos de América condicionó el reconocimiento al presidente Obregón a que firmara los llamados "Tratados de Bucareli" (lo cual hizo en 1923), a cambio de que no se aplicara la Constitución Mexicana a las empresas de Estados Unidos en materia petrolera; que se les indemnizara por los daños hubiese sufrido ciudadanos norteamericanos por los levantamientos entre los años 1868 y 1923 y que, por un periodo mínimo de 25 años, no se industrializara al país. Cfr. Alessio Robles, Vito, Desfile sangriento. Mis andanzas con nuestro Ulises. Los Tratados de Bucareli, México, Editorial Porrúa, S. A. 1979, p. 388. ISBN 968-432-381-6.
}

3 Diario Oficial de la Federación, 2 de julio de 1926. No es cuestión menor el que la mencionada ley, además de tener el vicio de origen de que el Ejecutivo, al legislar, violaba el Artículo 49 Constitucional y que dicha ley, casualmente, tenía 33 artículos.

4 Las leyes anticatólicas estuvieron vigentes en México hasta la reforma constitucional de 1992.

5 Degollado Guízar, Jesús, Memorias del último general en jefe del ejército cristero, México, Editorial Jus, 1957, p. 278 Es notable la amargura que expresa el general Degollado Guízar cuando en el licenciamiento de las fuerzas cristeras expresa: "Cómo hombres, cábenos también otra satisfacción, que jamás podrán arrebatarnos nuestros contrarios: la Guardia Nacional (sic) desaparece, no vencida por sus enemigos sino, en realidad, abandonada por aquellos que debían recibir, los primeros, el fruto valioso de sus sacrificios y abnegaciones. - ¡Ave, Cristo, los que por ti vamos a la humillación, al destierro, tal vez a una muerte ingloriosa, víctimas de nuestros enemigos, con todo rendimiento, con el más fervoroso de nuestros amores, te saludamos, y, una vez más, ¡te aclamamos Rey de nuestra patria! ¡Viva Cristo Rey! 
Posteriormente, el presidente Lázaro Cárdenas del Río (1934-1940) profundizó en la deriva del régimen hacia la izquierda ${ }^{6}$ y en el enfrentamiento contra la Iglesia Católica, lo que provocó la "Segunda Cristiada".

Ese era el entorno nacional e internacional que rodeó el nacimiento de la Unión Nacional Sinarquista. No es casual el que haya nacido en León, Guanajuato, del Bajío mexicano, teniendo sus principales centros de apoyo en los lugares en los que se habían tenido mayor presencia los cristeros. Por eso sus integrantes, que siempre defendieron la lucha pacífica, provenían de todas fuerzas que directa o indirectamente, habían sido apoyadas por la Iglesia Católica y que ideológicamente se nutrían de su doctrina social. Algunos de sus dirigentes pertenecían —o había pertenecido- a organizaciones secretas como "Las Legiones" y "La Base". Se trataba de una organización política conservadora que, aunque inicialmente se negaba a actuar como partido político que participara en las elecciones, pretendía ser fiel a la necesidad de que los católicos participaran activamente en la política, con el propósito de hacer una patria que encarnara los ideales católicos.

Cuando nace el sinarquismo, estaban triunfando las ideologías nazi-fascistas. En España, con Francisco Franco, triunfaban las fuerzas de la derecha, encabezadas por la Falange del José Antonio Primo de Rivera y, con la ayuda del nazifascismo, estaban venciendo a la república, que contaba con la ayuda de la Unión Soviética. Como había algunas afinidades ideológicas con esos movimientos, ${ }^{7}$ en la búsqueda de un patriotismo católico, el sinarquismo también copió parte de su estética como saludos, uniformes, brazaletes, educación paramilitar y, como algo más evidente, su bandera que, indefectiblemente, recuerda a la bandera nazi. ${ }^{8}$ Por eso - y por sus principios - se la ha considerado como un partido filo-nazi que, aparentemente, estaba en acuerdo con Alemania para que, eventualmente, sirviera a los intereses del expansionismo germano, menguando al imperialismo de Estados Unidos.

Al término de la Segunda Guerra Mundial todos los movimientos nazi-fascistas se habían desprestigiado, en parte por las atrocidades que habían cometido y en parte por el relato que de ellas hicieron las potencias vencedoras. Las excepciones eran la España de Francisco Franco, con la Falange, y el Portugal de Antonio de Oliveira Salazar, con su Estado novo. Ambos países, que fueron bloqueados durante varios años por las potencias vencederas, seguían manteniendo, en mayor o menor grado, las mismas ideologías con las que comulgaba al inicio el sinarquismo.

Entre los liderazgos sinarquistas que destaca el autor, es de mencionarse a Salvador Abascal, quien le dio al movimiento gran presencia en todo México, haciendo alarde de práctica católica combativa en el estado de Tabasco, en el cual

6 Entre otras muchas medidas, reformó el Artículo 3 constitucional, disponiendo que la educación en México sería "socialista".

7 Como su anticomunismo y su lucha contra la masonería.

8 Es roja, con un círculo blanco en medio, en el cual está, en verde, la silueta de México. Fuera del círculo están en blanco las letras UNS. 
se había recrudecido la lucha contra la Iglesia Católica. Siendo, como era, un político carismático, no sólo logró una gran concentración de católicos en Villahermosa (marzo 3 de 1938), en franco desafío al régimen anticatólico federal y estatal, que estaba en manos de Tomás Garrido Canaval, sino que también llevó al sinarquismo a su mayor expansión. ${ }^{9}$

Como menciona el autor, el sinarquismo estaba muy cerca de la Iglesia Católica y ésta también estaba en crisis. Entre los años 1962 y 1965 se había realizado el Concilio Vaticano II que, convocado por el Papa Juan XXIII y seguido por el Papa Paulo VI, pretendió la puesta al día de la Iglesia Católica ante "los signos de los tiempos". ${ }^{10}$ Sin embargo, esa puesta al día también provocó una división en la institución eclesiástica, habiéndose formado dos grupos irreconciliables: los progresistas y los tradicionalistas. Los primeros propugnaban por una mayor participación de la Iglesia en los problemas sociales, propiciando, en su extremo, la teología de la liberación, ello además de reformas litúrgicas que, en más de una ocasión, han estado cerca del sacrilegio. Los segundos querían seguir siendo fieles al Concilio de Trento (1545-1563) y se resistían a los cambios litúrgicos, así como a la reinterpretación de algunos dogmas que habían sido piedra angular de la Iglesia Católica, como el tantas veces mencionado por los Papas en los documentos oficiales de que "fuera de la Iglesia no hay salvación" (Extra Ecclesiam nulla salus), dado que la institución se abrió a "los hermanos separados".

La división en la Iglesia del postconcilio, que era fuente inspiradora del movimiento sinarquista, también incidió en éste y los sinarquistas estaban ante la disyuntiva de mantenerse con un movimiento político católico a ultranza, que sólo fuera un grupo de presión o que, por el contrario, de él naciera un partido político dentro de la institucionalidad.

La nueva realidad política hizo que, en varios países, la participación de los católicos en la política se hiciera por medio de la democracia cristiana, ante la cual, destacados líderes sinarquistas, como Celerino Salmerón, expresamente se querían distanciar, porque afirmaban que sólo se trataba de socialismo rociado por agua bendita. Sin embargo, otro grupo sí quería que del sinarquismo naciera un partido político, y así se gestó el nacimiento, en 1971, del Partido Demócrata Mexicano (PDM), el cual obtuvo su registro en 1978, mismo que perdió en las controvertidas elecciones de 1988, al haber obtenido sólo el $1.31 \%$ de los votos. ${ }^{11}$

$9 \quad C f r$. Borrego Escalante, Salvador, América peligra, México, 3a. ed., p. 653. También Abascal había creado una colonia de católicos, llamada "María Auxiliadora" en Baja California Sur (1942). "Abascal había sus cualidades de conductor de hombres y su acertada afirmación de que en esta clase de luchas el jefe debe serlo a la cabeza de todos los peligros. Más tarde habría de convertirse el organizador de las grandes concentraciones de Guanajuato, Guadalajara, Acámbaro y Morelia, hasta que su movimiento -indoblegable en ataques frontales - habría de ser escindido y debilitado por dentro".

10 Es un tópico el comentario de que el Papa Juan XXIII, a los pocos meses de su elección, abrió las ventanas del palacio apostólico y dijo: "Es necesario que entre la luz a la Iglesia" de ahí el aggiornamento.

11 Deliberadamente - o como referencia a la bandera de la UNS - la bandera del PDM indefectiblemente también parece añorar viejas "glorias": es roja con un círculo blanco en el cual está la silueta de un gallo, con las letras "PDM". 
El sinarquismo no había tenido partido político desde que, en 1949, se le canceló el registro al Partido Fuerza Popular.

Los sinarquistas formaban un partido político sin abandonar su lucha particular como Unión Nacional Sinarquista, buscando alianzas con partidos afines como el Partido Acción Nacional (PAN) con el que coincidían en algunos postulados, aunque los diferenciaban las bases, porque el sinarquismo tenía un fuerte apoyo entre los campesinos, en tanto que el PAN lo tenía en las clases medias y medias altas. El autor recuerda que en 1952 el sinarquismo apoyó totalmente a Efraín González Luna como candidato del PAN a la presidencia de la república, pero no lo hizo en 1964 con el también candidato del PAN José González Torres, a pesar de que éste había sido presidente de la Acción Católica de la Juventud Mexicana (ACJM).

El PDM aglutinó no sólo a sinarquistas, sino también personas que eran ajenas al movimiento y, lo que era más grave, a personas que no comulgaban con todo el ideario sinarquista. Por eso se dice que tuvo poco apoyo popular, porque había perdido la esencia derivada de su origen, y - como afirma el autor- en la actualidad continúa la discusión sobre la conveniencia de crear un nuevo partido político o mantenerse, como hasta ahora, como una asociación política nacional reconocida como tal, el 9 de abril de 1999. Quienes consideraron conveniente la creación de un nuevo partido político dieron vida al Partido Alianza Social que, aunque parezca irónico, en 2000 se unió al Partido de la Revolución Democrática, postulando para presidente de la república a Cuauhtémoc Cárdenas y a Andrés López Obrador para jefe en el entonces Distrito Federal. Ese mismo año, el Partido Alianza Social perdió su registro.

Finalmente, el autor cuestiona cuál puede ser el futuro de la Unión Nacional Sinarquista dado que, por una parte, quiere ser fiel a la razón de su existencia: ser un cauce para que los católicos tengan participación política que hagan posible una patria en la que se concrete la doctrina social de Iglesia Católica y, por otra parte, se enfrenta a una realidad liberal, en la cual ya no tienen cabida las ideas fundamentalistas de los años treinta. Sin embargo, el autor asegura que el estudio del sinarquismo es necesario porque, a pesar de toda la evolución social que ha tenido México, sigue habiendo un sustrato importante de mexicanos que están de acuerdo con la UNS en temas delicados de la agenda nacional, como el de la lucha contra el aborto y el de las uniones entre homosexuales.

La obra que se reseña constituye un estudio muy completo sobre el sinarquismo y no se puede entender la realidad política y social de México de los últimos cien años, si no se analiza a la Unión Nacional Sinarquista. 